\title{
Swimming training on moderate intensity significantly reduces total cholesterol and bodyweight on hypercholesterolemic rat model
}

\author{
Anindya Mar'atus Sholikhah*, Mochamad Ridwan \\ Universitas Negeri Surabaya. Jl. Lidah Wetan, Kec. Lakarsantri, Kota Surabaya, Jawa Timur 60213, \\ Indonesia \\ * Corresponding Author. Email: anindyasholikhah@unesa.ac.id
}

Received: July 18, 2020; Revised: January 11, 2021; Accepted: January 21, 2021

\begin{abstract}
It is well established that regular exercise has many positive benefits on health. Exercise at the appropriate intensity and level has been shown to improve lipid profile and reduce the risk of cardiovascular disease. This study investigates the effect of swimming training on total cholesterol levels and body weight in male Wistar rats. Thirty rats weighing 150-200 grams were randomly divided into one control (C) and two treatment groups (ST=swimming training, SED=sedentary activity). Rats in control (C) group were fed a standard diet, while rats in both treatment groups were fed high-fat diet-induced hypercholesterolemia for three weeks. Rats in ST were then swim-trained at moderate intensity for 30 minutes/day, six days a week for three weeks, and rats in SED were left without exercise stimuli. Body weight was measured weekly. At the end of the experimental period, intracardiac blood samples were drawn to measure the total cholesterol level. Findings revealed that rats' bodyweight $(p=0,045)$ and blood cholesterol $(\mathrm{p}=0,034)$ in ST group were significantly lower compared to SED. It indicates that swimming exercise is shown to be effective in weight loss and reducing blood cholesterol level in hypercholesterolemic rats.
\end{abstract}

Keywords: bodyweight, cholesterol level, aerobic exercise, hypercholesterolemia, swimming training

How to Cite: Sholikhah, A.M. \& Ridwan, M. (2021). Swimming training on moderate intensity significantly reduces total cholesterol and bodyweight on hypercholesterolemic rat model. Jurnal Keolahragaan, 9(1), 51-58, doi:https://doi.org/10.21831/jk.v9i1.33362

\section{INTRODUCTION}

Hyperlipidemia is a condition occurred due to lipid metabolism disorder in the human body, resulting in elevation of one or more plasma lipid concentration in blood, including the increase of triglycerides (TC) or hypertriglyceridemia; total cholesterol (TC) or hypercholesterolemia, low density lipoprotein or hyper-LDL cholesterolemia, and very low density lipoprotein (VLDL), along with the decrease of high density lipoprotein (HDL) (He \& Ye, 2020; Shattat, 2014; Vafa et al., 2011). The alterations of these different forms of lipids cause atherosclerosis which is characterized by the accumulations of plaques on the arterial walls, resulting in the narrowing and blockage of blood vessels (Sim et al., 2018; Wu et al., 2017). Atherosclerosis is associated with an increased risk of cardiovascular diseases, a number one leading cause of death and morbidity worldwide, taking over 17,9 million lives each year globally (Roever et al., 2017; WHO, 2017).

At present, the main treatment for atherosclerosis is drug intervention, but this treatment has its limitation and side effect (Wang \& Xu, 2017). Therefore, there is a need to find another safer, cheaper, and harmless option to prevent atherosclerosis. Thus, numerous studies have been done to investigate the risk factors of atherosclerosis, which is found later that the major risk factors is strongly associated with lifestyle, such as poor diet, smoking, and sedentarism (Lechner et al., 2020). Several meta analyses have also found that modification of lifestyle could improve the lipid and lipoprotein levels (Igarashi et al., 2019). And being physically active is one way to improve these lipid profiles.

It is well established that physical activity and regular exercise have beneficial effects in lowering the risk of chronic disease such as cancer, obesity, and type II diabetes (Sholikhah et al., 2018). Numerous studies have also demonstrated a positive effect of regular exercise to prevent the development of atherosclerosis (Khosravani et al., 2016), as well as improve immune part of healthy lifestyle. Regular exercise contributes to physical and physiological health (Ohuruogu, 2016), as well 
as mental well-being (Sosso \& Raouafi, 2017). Studies found that regular exercise improves immune system against free radical that can cause oxidative damage. When the volume and intensity are also taken into account, researchers agree that exercise with moderate intensity gives more positive benefits to health (Kyral et al., 2019; Ohuruogu, 2016; Riahi \& Riahi, 2016). Many professional authorities have suggested daily physical activity and aerobic exercise in moderate intensity to maintain physical fitness and lower the risk of non-communicable disease including hypercholesterolemia and obesity by engaging in running, walking, or swimming exercise.

Aerobic exercise is defined as any form body movement or activity that involves oxygen to produce the energy. Findings of previous studies revealed that aerobic exercise practices at regular basis changed lipid profiles on adults; it increased HDL level and decreased TC and LDL levels by 4 $\mathrm{mg} / \mathrm{dl}$ and $2 \mathrm{mg} / \mathrm{dl}$, respectively (Igarashi et al., 2019). Significant differences in TG, TC, and HDL were shown between exercised and non-exercised subjects (Elsayyad et al., 2020). Regular aerobic exercise also helps to reduce visceral fats, and it has been widely used to maintain and shape bodyweight. Studies on human and rats model using several method of training with low and moderate intensity resulted in adaptation mechanism on muscular and cardiorespiratory system, fat oxidation and weight loss (Nakhaei et al., 2019; Rocha et al., 2016). Thus, we conduct the study to investigate the effect of aerobic exercise in swimming training at moderate intensity on bodyweight and total cholesterol (TC) of rats fed with high-fat diet. Swimming training was chosen because swimming does not cause too much pressure on the body. Moreover, the four factors in swimming which are water, water pressure, water temperature, and buoyancy are used to present the stability and effect of this exercise can be optimized better than the effects of doing ground exercise (Lee \& Oh, 2015).

\section{METHOD}

A total of thirty male Wistar rats (Rattus norvegicus) weighing between 150-200 grams were used in this study. All rats were housed in standard cages and assigned to adapt under controlled conditions $\left(25 \pm 1^{\circ} \mathrm{C}\right.$ temperature; $50 \pm 1 \%$ relative humidity; and 12-h alternate light/dark cycle). During one week of acclimatization period, they were fed normal diet and tap water ad libitum. Afterward, they were divided into three weight-matched groups; one control (standard diet, no intervention) and two treatment groups (ST and SED). ST group was given high-fat diet and then submitted to aerobic exercise which is swimming training at moderate intensity every morning. Meanwhile, rats in SED group were only given high-fat diet with no exercise stimuli. High fat diet was prepared by adding $10 \%$ of liquid mixture of reused cooking oil and egg yolk to standard rat chow.

The swimming session was done in a tank filled up with water that was sufficient enough for rats to swim simultaneously without touching the bottom of the tank. The swimming training at the first week began with acclimatization in the water for 15 minutes. Then, the duration was increased by 5 minutes every day until each rat could swim continuously for 30 minutes. Swimming training was performed regularly, six days a week for three weeks (Riahi \& Riahi, 2016). After each swimming session, rats were hair-dried to prevent hypothermia stress.

During experimental period, average food intake of each group was recorded daily and bodyweight was measured weekly. At the end of the last week, all rats were euthanized following a 12-h fasting period. Intracardiac bloods were drawn to measure serum total cholesterol level.

Data were analyzed with statistical software and were presented as mean values and standard deviation (SD). One way Annova was performed to compare bodyweight and total cholesterol level between groups. Paired t-test was performed to compare the initial and final bodyweight. Pearson correlation was performed to determine the correlation between bodyweight and total cholesterol level. $\mathrm{P}<0,05$ was considered statistically significant.

\section{RESULT AND DISCUSSION}

This study investigated the effects of swimming training on bodyweight and total cholesterol level in animal model. All rats in three groups were healthy and did not show any significant changes after a week of acclimatization and they completed the whole protocol until the end of experimental period. 


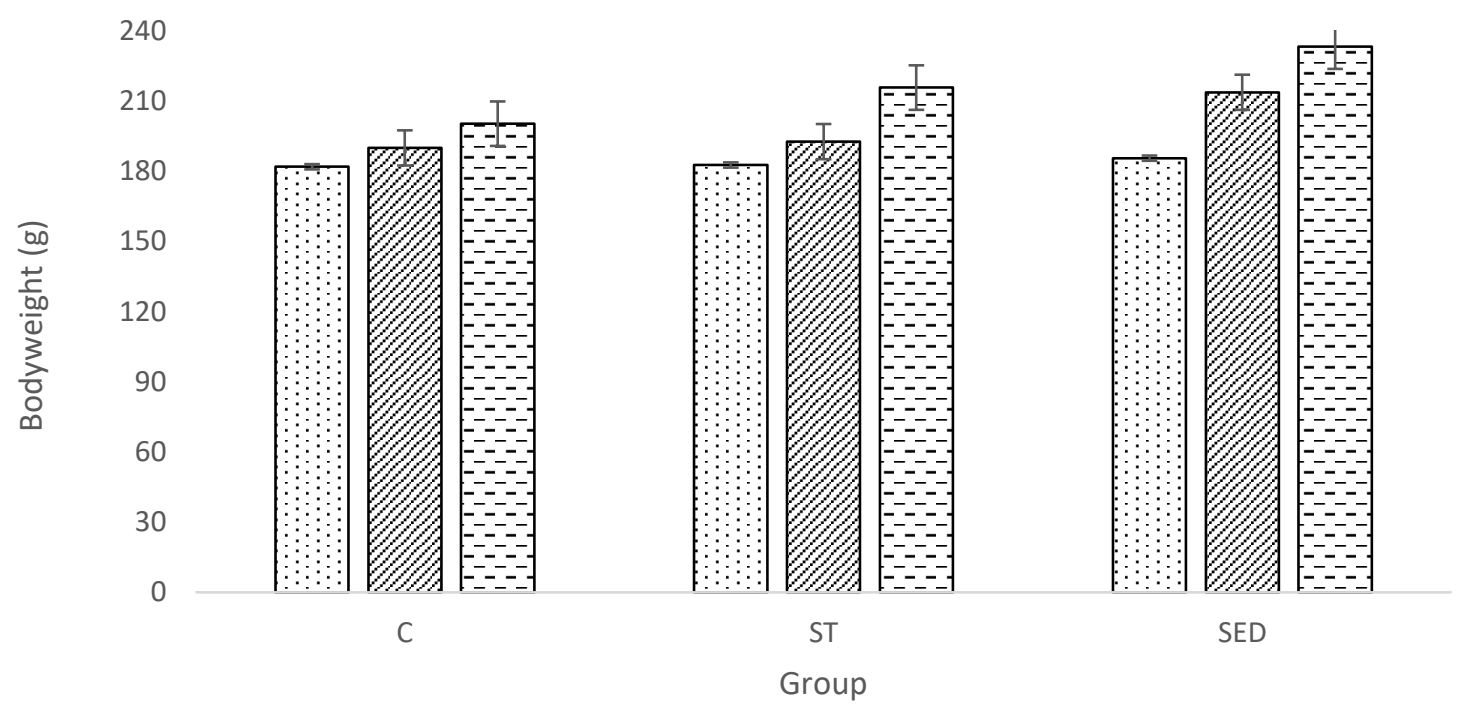

曰week 1 øweek 2 घweek 3

Figure 1. The changes in bodyweight by week. $C=$ control group-normal diet; $S T=$ swimming training-high fat diet; SED=sedentary activity-high fat diet. Data were presented as mean $\pm \mathrm{SEM}$

Figure 1 showed the changes in bodyweight during three weeks of experimental period. Bodyweight was measured at the first day of each week. We observed the increases of bodyweight in all groups during three weeks of experiment, but control group did not show significant increase. Bodyweight in swimming training and sedentary group started to increase significantly in week 2 $(p<0,05)$ and week $3(p<0,05)$. However, weight gain in swimming training group was lower than in sedentary peers, and it was found that exercise significantly contributed to reduce weight gain in highfat diet rats.

Table 1. Effect of swimming training and high-fat diet on the changes of initial and final bodyweight

\begin{tabular}{|c|c|c|c|c|}
\hline \multirow{2}{*}{ Group } & \multicolumn{2}{|c|}{ Bodyweight $(\mathrm{g})$} & \multirow{2}{*}{ Weight Gain $(\mathrm{g})$} & \multirow{2}{*}{ Sig. } \\
\hline & First Week & Last Week & & \\
\hline Control-Normal Diet (C) & $181,95 \pm 7,30$ & $200,37 \pm 7,01$ & $18,42 \pm 6,39$ & 0,066 \\
\hline Swimming Training-High Fat Diet (ST) & $182,71 \pm 5,08$ & $215,80 \pm 7,85$ & $33,10 \pm 6,01$ & $0,045^{*}$ \\
\hline Sedentary-High Fat Diet (SED) & $185,63 \pm 5,76$ & $233,30 \pm 6,38$ & $47,67 \pm 4,96$ & $0,034 *$ \\
\hline
\end{tabular}

*significant at 0,05

Data were represented as mean $\pm \mathrm{SD}$

The initial bodyweight of rats in control, swimming training, and sedentary group was $181,95 \pm$ 7,30 gram, 182,71 $\pm 5,80$ gram, and 185,63 $\pm 5,76$ respectively. And after three weeks of intervention, rats in all groups started to gain weight. However, results showed an insignificant increment of bodyweight gain in control group ( $\mathrm{p}=0,066, \mathrm{p}>0,05)$. Meanwhile, significant different of bodyweight were found in ST $(p=0,045, p<0,05)$ and SED $(p=0,034, p<0,05)$. High fat diet-induced hypercholesterolemia significantly increased bodyweight, however when hypercholesterolemic rats were given swimming training at moderate intensity, the weight gain was lower compared to sedentary group $(\mathrm{p}<0,05)$.

Table 2. Effect of swimming training and high-fat diet on changes in total cholesterol level

\begin{tabular}{lc}
\hline \multicolumn{1}{c}{ Group } & Total Cholesterol Level (mg/dl) \\
\hline Control-Normal Diet (C) & $52,86 \pm 1,08^{\mathrm{a}, \mathrm{c}}$ \\
Swimming Training-High Fat Diet (ST) & $56,87 \pm 0,65^{\mathrm{a}, \mathrm{b}}$ \\
Sedentary-High Fat Diet (SED) & $62,68 \pm 0,87^{\mathrm{b}, \mathrm{c}}$ \\
\hline
\end{tabular}

$\mathrm{a}=$ Significant different between control and swimming training high-fat diet $(\mathrm{p}<0,05)$;

$\mathrm{b}=$ Significant different between swimming training high-fat diet and sedentary $(\mathrm{p}<0,05)$;

$\mathrm{c}=$ Significant different between control and sedentary $(\mathrm{p}<0,05)$ 
The results showed that diet enriched far given for three weeks affected rat's lipid profile (Table 2). It marked with a significant increase of total cholesterol levels in rats which fed high-fat diet (SED) compared to control group $(\mathrm{p}<0,05)$. But when hypercholesterolemic rats were given swimming training for three weeks (ST), the increase of total cholesterol levels was significantly lower compared to hypercholesterolemic group with no exercise at all (SED) $(\mathrm{p}<0,05)$. Weight gain was positively correlated with total cholesterol level of rats, both in control group and treatment group (ST and SED) with $\mathrm{p}<0,05$ and $\mathrm{r}=0,828$ (Table 3 ).

Table 3. The overall correlation between weight gain and total cholesterol level

\begin{tabular}{cccc}
\hline Weight Gain $(\mathrm{g})$ & Total Cholesterol Level $(\mathrm{mg} / \mathrm{dl})$ & $\mathrm{r}$ & Sig. \\
\hline $33,06 \pm 13,38$ & $57,47 \pm 4,19$ & 0,828 & 0,000 \\
\hline
\end{tabular}

\section{Effect of swimming training on bodyweight in rats fed high-fat diet}

Diet manipulation which given in this research was the mixture of reused cooking oil and egg yolk. Reused cooking oil contains high trans isomers saturated fatty acids. Due to several reheating process, unsaturated fatty acid undergo chemical changes that generated several oxidized products, leading to deleterious effects on the vascular function (Leong et al., 2015). This research also used egg yolk, which contains 13,2 gram monounsaturated fatty acid, 3,4 gram polyunsaturated fatty acid, 8,7 gram saturated fatty acid, and $1.120 \mathrm{mg}$ per 100 gram of fresh egg yolk (Faitarone et al., 2013). The combination of these high-fat diet will increase the fat accumulation in body, which later promotes weight gain.

The high-fat diet given to rats in ST and SED group resulted in greater increase of bodyweight compared to rats in control group that were fed normal diet. This finding was similar to Nissa \& Madjid (2016) that observed an increase of bodyweight in rats fed fat-enriched diet consisted of flour, coconut oil, duck yolk, and lard. High-fat diet is known to induce positive fat balance that leads to adipose mass accumulation (Coelho et al., 2011) and enlarged the size of adipocyte cells (Cani et al., 2007). High-fat diet also do not stimulate fat oxidation rate in the same way in obese and lean subjects (Westertep et al., 2008). The type of dietary fat also seems to be a possible determinant in the elevation of body fat. For example, diets rich in saturated lipids can increase body fat stores to a greater extent when compared to omega-3 and omega-6-rich diet (Coelho et al., 2011). Present study also found that the decrease in total cholesterol level could be expected upon weight loss.

The result was also supported by a previous study conducted by Cani et al. (2008) that stated the induction of a high-fat diet in mice was able to promote bodyweight through the modulation of intestinal microbiota, resulting in increased intestinal absorption ability and its permeability. Increased free fatty acids that accumulate in the tissues will increase the accumulation of long-chain acyl-CoA and its metabolites including intracellular ceramides, diacylglycerol (DAG), and triacylglycerol (TAG). Ceramides accumulation triggers dephosphorylation of protein kinase B/Akt (PKB/Akt). PKB/Akt dephosphorylation induces glucose transport to tissues through increased glucose transporter-4 (GLUT-4) activity resulting in an increase in glycogenesis (King, 2013). PKB/Akt dephosphorylation also inhibits tissue lipolysis and gluconeogenesis (Vardatsikor et al., 2013). Increased glucose uptake to tissues and glycogenesis and also downregulation of lipolysis and gluconeogenesis cause an increase in body mass. This mechanism explains why a high-fat diet can be used as an induction of hyperlipidaemia as it could significantly increase bodyweight (Nissa \& Madjid, 2016).

Meanwhile, when high-fat fed rats performed regular exercise, the weight gain was slightly lower than those in sedentary peers. In accordance with this finding, another study also showed that physical activity reduced bodyweight in rats given fat-enriched diet (Rocha et al., 2016). It can be explained because a stress agent generated during exercise may modulate the release of anoretic hormones and/or increase its receptors sensitivity. These conditions lead to the suppressing of appetite and manage to shift the energy balance during exercise or physical training (Blundell et al., 2015; Schubert et al., 2012).

The reduce of bodyweight is also associated with energy balance. Exercise is known to be directly impacted the energy expenditure and modulation of energy intake (EI), thus it has negative effects on energy balance (Riahi \& Riahi, 2016). Physical activity and exercise elevates energy expenditure and the contribution of fat oxidation to energy expenditure is most pronounced when 
exercise was performed in low and moderate intensity (Van Baak, 1999). Thus, subjects who engaged in exercise and physical training showed lower adiposity tissue than subjects who took part in sedentary activity.

During aerobic exercise, fat is the most used to provide energy for muscle contraction (Eberle, 2013). This energy comes from the breakdown of ATP reserves. ATP in muscle fibers is obtained through 3 ways; (1) direct phosphocreatine-ATP pathway; (2) the glycolytic pathway; and (3) the oxidative pathway. Oxidative pathways are the main source of ATP production. ATP is produced by oxidation of free fatty acids derived from the hydrolysis of triglycerides from adipose tissue and from the diet. For each molecule, fat oxidation requires more oxygen. In light intensity aerobic exercise (LIIT), due to sufficient time, the cardiovascular system is still able to meet the oxygen demand of the contracting muscle, which lead to the continuous use of fat as the main energy source. The fat as an energy source can be obtained from the unloading of storage fat tissue, such as subcutaneous and visceral fat tissue. The use of body fat in aerobic activity with low to moderate intensity will cause a reduction in storage fat, thus it automatically reduces the overall bodyweight (Van Baa k, 1999).

\section{Effect of swimming training on total cholesterol level in rats fed high-fat diet}

Cholesterol is a substance that mostly found in animal products such as poultry, meat, and dairy products (Shazamawati et al., 2013). It presents in all tissues in the form of free cholesterol or a combination of long-chain fatty acid. Cholesterol is synthesized from acetyl-co-A in liver which then released through the bile. This substance is pretty much needed in the body to produce certain hormones, insulate nerves, and form cell membranes. But, high cholesterol in serum plasma will causes a built-up plaque that can narrowing the arterial wall and blocking the blood flow (Ma \& Shieh, 2006). The concentration of cholesterol in blood will increase, resulting a state of hypercholesterolemia. In Wistar rats, hypercholesterolemia occurs when blood cholesterol is beyond $54 \mathrm{mg} / \mathrm{dl}$ (Harini \& Astirin, 2009).

Study about the effects of dietary cholesterol on health has been developing over the past four decades ago. Studies on animal model revealed that cholesterol-enriched diet consisted of egg yolk that were given to animal include rhesus monkey resulted in the increase of lipid profile (Spence et al., 2010). The present study showed that total cholesterol level increased after rats were given high-fat diet for three consecutive weeks. The significant increase of TC level was also observed by Harini \& Astirin (2009) after feeding rats with lard rich in saturated fatty acid. The elevation of TC level due to the increase accumulation of fat in the liver, resulting in rising number of acetyl-co-A in liver cells to produce cholesterol. Acquired high cholesterol due to high-fat diet combined with sedentary activity will lead to hypercholesterolemia, a condition that underlies the morbidity and deaths caused by vascular disease such as CHD.

The results of present study showed that swimming exercise altered TC level in hypercholesterolemic rats. Total cholesterol level in rats assigned to swimming exercise was lower than rats given no exercise. These findings were similar to Harini \& Astirin (2009) and Rocha et al. (2016) who obtained an increase of serum lipid profile including total cholesterol after rats being fed high-fat diet. Study in human also reported that exercise at moderate intensity is assumed to be sufficient to improve lipid profiles in East Asian subjects (Igarashi et al., 2019). Previous meta analysis studies observed the significant elevation of lipid and lipoprotein levels as a result of regular aerobic exercise (Kelley et al., 2012, 2013). The mechanism regarding how exercise improved lipid and lipoprotein is still unclear, however, several processes may take into account for this such as adipocytokine and insulin resistance. Nevertheless, it is important to understand that exercise itself may promote blood lipid consumption, therefore it can reduce lipid levels.

Previous studies revealed that the exercise-induced changes in blood lipids also associated with exercise duration, volume, and intensity. Kraus et al. (2002) explained in their research that exercise intensity and total energy consumption were the main factor affecting the alteration of lipid profile. Further results observed by O'Donovan et al. (2005) found that in the same amount of exercise, the changes in blood lipid were more pronounced in exercise with higher intensity. Thus, many studies suggested moderate intensity exercise than high and low intensity to induce the changes in blood lipid in general, including total cholesterol level. 


\section{CONCLUSION}

This study revealed the beneficial effect of moderate-intensity swimming training on reducing bodyweight and total cholesterol level in hyperlipidemic rat model. The results suggest an efficient non-medicine strategy to control bodyweight and total cholesterol changes associated with high-fat diet.

\section{REFERENCES}

Blundell, J. E., Gibbons, C., Caudwell, P., Finlayson, G., \& Hopkins, M. (2015). Appetite control and energy balance: impact of exercise. Obesity Review, 16, 67-76.

Cani, P. D., Amar, J., Iglesias, M. A., Poggi, M., Knauf, C., Bastelica, D., Neyrinck, A. M., Fava, F., \& Al, E. (2007). Resistance. Diabetes, 56(July), 386-389. https://doi.org/10.1016/B978012373947-6.00332-9

Cani, P. D., Bibiloni, R., Knauf, C., Waget, A., Neyrinck, A. M., Delzenne, N. M., \& Burcelin, R. (2008). Changes in gut microbiota control metabolic endotoxemia-induced inflammation in highfat diet-induced obesity and diabetes in mice. Diabetes, 57(6), 1470-1481. https://doi.org/10.2337/db07-1403

Coelho, D. F., Chaves, D. S., Diwan, D., Ferraz, R., Poortmans, J. R., \& Junior, A. H. L. (2011). Effect of high-fat diets on body composition, lipid metabolism and insulin sensitivity, and the role of exercise on these parameters. Brazilian Journal of Medical and Biological Research, 44(10), 966-972. https://doi.org/10.1590/S0100-879X2011007500107

Eberle, S. G. (2013). The Body's Fuel Sources. In Endurance Sports Nutrition-3rd Edition. Human Kinetics Inc. https://us.humankinetics.com/blogs/excerpt/the-bodys-fuel-sources

Elsayyad, L., Allam, H., AAlzahrani, N., Gharib, A. F., Shami, A., Khalifa, O. M., \& Ismail, K. A. (2020). Effect of short-term aerobic exercise on lipid profile. Annals of Clinical Medicine and Research, 1(1), 5-7.

Faitarone, A. B. G., Garcia, E. A., Roca, R. O., Ricardo, H. A., Andrade, E. N., Pelicia, K., \& Vercese, F. (2013). Cholesterol levels and nutritional composition of commercial layers eggs fed diests with different vegetable oils. Brazilian Journal of Poultry Science, 15(ISSN 1516-635X), 31-38.

Harini, M., \& Astirin, O. P. (2009). Blood cholesterol levels of hypercholesterolemic rat (Rattus norvegicus) after VCO treatment. Nusantara Bioscience, 1(2), 53-58.

He, N., \& Ye, H. (2020). Exercise and hyperlipidemia. In J. Xiao (Ed.), Physical Exercise for Human Health (pp. 79-90). Springer. https://doi.org/10.1007/978-981-15-1792-1_5

Igarashi, Y., Akazawa, N., \& Maeda, S. (2019). Effects of aerobic exercise alone on lipids in healthy east asians: A systematic review and meta-analysis. Journal of Atherosclerosis and Thrombosis, 26(5), 488-503. https://doi.org/10.5551/jat.45864

Kelley, G. A., Kelley, K. S., Roberts, S., \& Haskell, W. (2012). Combined effects of aerobic exercise and diet on lipids and lipoproteins in overweight and obese adults: a meta-analysis. Journal of Obesity, 2012(986902). https://doi.org/10.1155/2012/985902

Kelley, G. A., Kelley, K. S., Roberts, S., \& Haskell, W. (2013). Comparison of aerobic exercise, diet or both on lipids and lipoproteins in adults: a meta analysis of randomized controlledd trials. Clinical Nutrition, 31(2), 156-167. https://doi.org/10.1016/j.clnu.2011.11.011.Comparison

Khosravani, M., Azarbayjani, M. A., Abolmaesoomi, M., Akbari, M., Yusof, A., Abidin, N. Z., Rahimi, E., \& Seyedjalali, S. (2016). Ginger extract and aerobic training reduces lipid profile in high-fat fed diet rats. European Review for Medical and Pharmocological Sciences, 20, 16171622.

King, M. W. (2013). Diabetes Mellitus. [Series Online]. http://thebiomedicalbiochemistrypage.org

Kraus, W., Houmard, J., Duscha, B., \& Al, E. (2002). Effects of the amount and intensity of exercise on plasma lipoproteins. The New England Journal of Medicine, 347(19), 1483-1492.

Kyral, A. M., Shipherd, A. M., \& Hearon, C. M. (2019). The Effect of Moderate Intensity Aerobic Exercise on Affect and Exercise Intention in Active and Inactive College Students. International Journal of Exercise Science, 12(5), 1070-1079. 
Lechner, K., von Schacky, C., McKenzie, A. L., Worm, N., Nixdorff, U., Lechner, B., Kränkel, N., Halle, M., Krauss, R. M., \& Scherr, J. (2020). Lifestyle factors and high-risk atherosclerosis: Pathways and mechanisms beyond traditional risk factors. European Journal of Preventive Cardiology, 27(4), 394-406. https://doi.org/10.1177/2047487319869400

Lee, B. A., \& Oh, D. J. (2015). Effect of regular swimming exercise on the physical composition, strength, and blood lipid of middle-aged women. Journal of Exercise Rehabilitation, 11(5), 266271.

Leong, X.-F., Ng, C.-Y., Jaarin, K., \& Mustafa, M. (2015). Effects of repeated heating of cooking oils on antioxidant content and endothelial function. Austin Journal of Pharmacology and Therapeutics, 3(2), 1068.

Ma, H., \& Shieh, K. J. (2006). Cholesterol and human health. The Journal of American Science, 2(1), $46-50$.

Nakhaei, H., Mogharnasi, M., \& Fanaei, H. (2019). Effect of swimming training on levels of asprosin, lipid profile, glucose and insulin resistance in rats with metabolic syndrome. Obesity Medicine, 15(April), 100111. https://doi.org/10.1016/j.obmed.2019.100111

Nissa, C., \& Madjid, I. J. (2016). Potensi glukomanan pada tepung porang sebagai agen anti-obesitas pada tikus dengan induksi diet tinggi lemak. Jurnal Gizi Klinik Indonesia, 13(1), 1-6.

O’Donovan, G., Owen, A., Bird, S., \& Al, E. (2005). Changes in cardiorespiratory fitness and coronary heart disease risk factors following $24 \mathrm{wk}$ of moderate- or high intensity exercise of equal energy cost. Journal of Applied Physiology, 98(5), 1619-1625.

Ohuruogu, B. (2016). The contributions of physical activity and fitness to optimal health and wellness. Journal of Education and Practice, 7(20), 123-128.

Riahi, F., \& Riahi, S. (2016). Effects of moderate swimming exercise on weight gain in high fat diet rats. Annals of Military \& Health Sciences Research, 14(1), 46-50.

Rocha, G. L., Crisp, A. H., Oliveira, M. R. M. De, Silva, C. A., Silva, J. O., Duarte, A. C. G. O., Senefiorese, M., \& Verlengia, R. (2016). Effect of high intensity interval and continuous swimming training on body mass adiposity level and serum parameters in high-fat diet fed rats. The Scientific World Journal, 2016. https://doi.org/10.1155/2016/2194120

Roever, L., Resende, E. S., Diniz, A. L. D., Penha, S. N., Roerver, B. A. S., Veloso, V. C., Casella, F. A., Dourado, P. M. M., \& Chagas, A. C. P. (2017). Major risk factors for atherosclerosis and metabolic syndrome: The UHS. Interventional Cardiology, 09(05), 199-203. https://doi.org/10.4172/interventional-cardiology.1000578

Schubert, M. M., Desbrow, B., Sabapathy, S., \& Leveritt, M. (2012). Acute exericse and subsequent energy intake. A meta analysis. Appetite, 63, 92-104. https://doi.org/10.1016/j.appet.2012.12.010

Shattat, G. F. (2014). A review article on hyperlipidemia: types, treatments, and new drug targets. Biomedical and Pharmacology Journal, 7(2). https://doi.org/10.13005/bpj/504

Shazamawati, Z. H., Alina, A. R., Mashitoh, A. S., \& Juhana, M. J. T. (2013). Cholesterol oxidation products analysis in meat and poultry. Middle-East Journal of Scientific Research, 16, 67-78. https://doi.org/0.5829/idosi.mejsr.2013.16.s.100212

Sholikhah, A. M., Wirjatmadi, B., \& Andriyani, M. (2018). Effects of purple sweet potatoes on oxidative stress biomarkers in rats subjected to exhaustive exercise. Health Notions, 2(2), 174 177.

Sim, J., Hwang, S., \& Song, C. (2018). Hyperlipidemia as a predictor of physical functioning for stroke. Physical Therapy Rehabilitation Science, 7, 88-93. https://doi.org/10.14474/ptrs.2018.7.2.88

Sosso, F. A. E., \& Raouafi, S. (2017). An overview of positive interaction between exercise and mental health. Journal of Neurology and Neuroscience, 08(04), 17-20. https://doi.org/10.21767/2171-6625.1000215

Spence, J. D., Jenkins, D. J. A., \& Davignon, J. (2010). Dietary cholesterol and egg yolks: Not for patients at risk of vascular disease. Canadian Journal of Cardiology, 26(9), 336-339. https://doi.org/10.1016/S0828-282X(10)70456-6 
Jurnal Keolahragaan 9 (1), 2021 - 58

Anindya Mar'atus Sholikhah, Mochamad Ridwan

Vafa, M. R., Haghighatjoo, E., Shidfar, F., Afshari, S., Gohari, M. R., \& Ziaee, A. (2011). Effects of apple consumption on lipid profile of hyperipidemic and overweight men. International Journal of Preventive Medicine, 2(2), 94-100.

Van Baak, M. A. (1999). Physical activity and energy balance. Public Health Nutrition, 2 (3 A), 335339. https://doi.org/10.1017/S1368980099000452

Vardatsikor, G., Pandey, N. R., \& Srivastava, A. K. (2013). Insulino-mimetic and anti-diabetic effects of zinc. Journal of Inorganic Biochemistry, 120, 8-17. https://doi.org/10.1016/j.jinorgbio.2012.11.006

Wang, Y., \& Xu, D. (2017). Effects of aerobic exercise on lipids and lipoproteins. Lipids in Health and Disease, 16(1), 1-8. https://doi.org/10.1186/s12944-017-0515-5

Westertep, K. R., Smeets, A., Lejeune, M. P., Wouters-Adriaens, M. P. E., \& Westerterp-Plantenga, M. S. (2008). Dietary fat oxidation as a function of body fat. The American Journal of Clinical Nutrition, 87, 132-135.

WHO. (2017). Cardiovascular diseases (CVDs). https://www.who.int/news-room/factsheets/detail/cardiovascular-diseases-(cvds)

Wu, M. Y., Li, C. J., Hou, M. F., \& Chu, P. Y. (2017). New insights into the role of inflammation in the pathogenesis of atherosclerosis. International Journal of Molecular Sciences, 18(10). https://doi.org/10.3390/ijms18102034 